\title{
Evolving Prehospital, Emergency Department, and "Inpatient" Management Models for Geriatric Emergencies
}

\author{
Christopher R. Carpenter, MD, MSc and Timothy F. Platts-Mills, MD
}

\begin{abstract}
Alternative management methods are essential to ensure high quality and efficient emergency care for the growing number of geriatric adults worldwide. Protocols for case-finding and rapid diagnosis to support early condition-specific treatment for older adults with acute severe illness and injury are needed. Improved emergency department care for older adults will require providers to look beyond the diagnosis to address the influence of other factors on the patient's health: isolation and depression; finances and transportation; and chronic medical conditions and polypharmacy. This review article describes recent and ongoing efforts to enhance the quality of emergency care for older adults using alternative management approaches spanning the spectrum from prehospital care, through the emergency department, and into evolving inpatient or outpatient processes of care.
\end{abstract}

\section{Keywords}

Geriatrics; Emergency Medical Services; Emergency Service, Hospital; Case Management/ Organization and Administration; Models/Organizational

\section{Introduction}

\begin{abstract}
A historically unprecedented expansion of the world's geriatric population over the next four decades will challenge prehospital emergency medical services, healthcare providers, and hospital administrators to adapt the $20^{\text {th }}$ Century infrastructure and management models in order to maintain reliable access to Emergency Medicine (EM) care.[1-5] EM nurses and physicians already identify geriatric patients as a significant source of clinical stress due to the higher burden of severe illness and injury and the greater complexity of medical decision making encountered in caring for this population.[6-10] The traditional emergency care model (Figure 1a) focuses on purely diagnostic and therapeutic medical decision-making, whereas the geriatric emergency care model incorporates essential elements of older adult well-being including social isolation, transportation limitations, fixed incomes, cognitive status, and functional disability (Figure 1b).[11] Although the format and extent of change to existing organizations will depend upon local resource availability and anticipated demand, almost every healthcare system will need to adjust to some degree.[12] In addition, current policies that provide financial disincentives to short-term readmissions for common diagnoses have expanded the domain of EM to include the spectrum from proactive
\end{abstract}

(C) 2012 Elsevier Inc. All rights reserved

Publisher's Disclaimer: This is a PDF file of an unedited manuscript that has been accepted for publication. As a service to our customers we are providing this early version of the manuscript. The manuscript will undergo copyediting, typesetting, and review of the resulting proof before it is published in its final citable form. Please note that during the production process errors may be discovered which could affect the content, and all legal disclaimers that apply to the journal pertain.

No conflicts of interest to declare. 
preventive care by prehospital providers to a paradigm shifting concept of the "hospital-athome". This chapter will explore these evolving management models within the context of contemporary emergency care for geriatric adults.

The objective of EM care for the aging adult is to alleviate suffering while providing prompt diagnosis of life-threatening pathology in order to prolong the quality of life while respecting patient and family autonomy. Chronological age is not always synonymous with physiological age so there is neither a "one size fits all" approach nor an age-based approach to care. Instead, optimal care of the older adult requires attention to the psychosocial dynamic between the patient and the patient's family or care providers, thus distinguishing geriatric care from the traditional EM care model (see Figures 1a and 1b).[11] Emergency department (ED) management that neglects geriatric care principles produces suboptimal outcomes.[13] Therefore, these principles should be incorporated into prehospital provider and EM residency education. Unfortunately, EM graduate medical education has not emphasized geriatric principles in the past.[14]

Whereas the younger patient typically presents to the ED with a symptom-based chief complaint that is generally amenable to a focused diagnostic and therapeutic approach, geriatric adults more commonly report atypical or non-specific symptoms that prompted the patient or their fatigued caregiver to seek medical care.[15] Although these symptoms can be the manifestation of an acute and reversible life-threatening illness, more often the symptoms are a result of a complex mix of chronic disease processes, some of which have not yet been diagnosed. In addition, the presenting complaint, whether life-threatening or not, may represent just one of the threats to the older patient's well-being, a situation which is far less likely in younger populations.[16, 17] These hidden threats are often viewed as outside the domain of traditional EM care and include physical or emotional isolation and neglect,[18, 19] economic disparities, polypharmacy,[20-22] functional and cognitive decline,[23, 24] malnutrition, [25, 26] fall risk,[27, 28] and inadequate access to transportation. In order to provide optimal evidence-based care incorporating geriatric principles, future EM management models will need to incorporate a sufficiently robust and adaptable organization that incorporates appropriately trained personnel, reliable streams of communication between prehospital, ED, inpatient, and outpatient services, valid protocols, and a geriatric-friendly infrastructure. $[3,8]$

\section{Prehospital Geriatric Care Opportunities}

Because older adults often require assistance with transportation to the ED, prehospital providers have and will likely continue to care for a disproportionate number of older patients. As of 2007, emergency medical services (EMS) transports of adults age 65 and older comprised 38\% of all US EMS transports.[29] In some regions, transports of older adults are anticipated to exceed 50\% of total EMS transports in the next decade.[29, 30] In 2003, the American Geriatrics Society and the National Council of State EMS Training Coordinators developed the Geriatric Education for Emergency Medicine Services (GEMS) curriculum.[31] Providers who have completed the GEMS course report improvement in communication, abuse assessments, and falls evaluation with elderly patients.[32] Internetbased learning for EMS providers is also possible.[33]

EMS providers are willing to promote geriatric health through proactive screening programs that extend beyond the traditional scoop-and-run approach, but simple screen-and-refer pathways are ineffective. [34, 35] The burden of EMS care for older adults has generated three major areas of inquiry:[36] expressed here as questions: 
1) For older adults with acute severe illness and injury, are there ways to improve the capacity of EMS providers to diagnose specific conditions in order to provide early treatment?

2) For older adults with non-severe conditions, are there alternatives methods of providing care which are less costly than the traditional approach of EMS transport, ED evaluation, and EMS return transport?

3) Can prehospital providers serve as public health stewards by conducting rapid screening assessments to identify older adults in the community at high risk for adverse events?

Progress on each of these areas of inquiry is described below.

Specific time-sensitive diseases that might benefit from rapid diagnostics include myocardial infarction, stroke, and trauma. Although EKGs in the prehospital setting are now broadly used, protocols which recognize that the majority of older adults with ST-elevation myocardial infarction do not have chest pain have not been broadly implemented.[37] Prehospital stroke protocols have been developed and validated and have the potential to accelerate access to thrombolytic therapy.[38] However, the public health impact of these protocols is limited by the controversial benefit to risk ratio of thrombolytics for stroke in any age groups and specifically in geriatric stroke patients.[39-47] In prehospital trauma care injury severity tends to be under-recognized in older adults, $[48,49]$ a problem that also occurs when older patients reach the ED.[50] The incorporation of age into trauma assessments may help to prevent under-triage of older trauma patients.

Alternatives methods of providing prehospital care for older adults who might otherwise seek care in the ED has the potential to reduce costs. Any such approach must also have the capacity to identify patients with time-sensitive illness and injury. One option is telemedicine, in which a patient assessment by a physician verbally and visually is via audio and video transmissions. Telemedicine is currently being studied as a method of reducing ED visits. Telemonitoring of older adults involves daily assessments using the same technology, but a randomized study did not find that this approach reduced ED visits or hospitalizations.[51] Increased access to primary care following an EMS evaluation has been shown to decrease ED use.[52, 53] However, access to primary care for older US adults continues to be a problem, reflecting both reimbursement problems and personnel shortages.[54, 55]

The potential of prehospital providers to screen older adults for risk of falls, depression, or medication mismanagement has been demonstrated.[56] Prehospital screening for fall risk has yielded equivocal outcomes, but prospective referrals during the initial in-home evaluation are superior to retrospective EMS medical record review and refer models.[5760] Ongoing research will assess the effectiveness of EMS fall screening in the near future. [61, 62] The impact of EMS screening on ED use and other health outcomes has not been evaluated. Given the large number of at risk older adults with limited access to primary care in the United States (US),[63] there is a large potential value in developing the capacity of EMS providers to identify older adults most likely to benefit from increased access to health care. Implementing this type of preventive care broadly will require both additional research demonstrating an impact on important outcomes and mechanisms to reimburse EMS systems.[64, 65]

\section{The Geriatric Emergency Department}

One method by which to classify ED clinical services for geriatric adults is to assess the availability of human resources, care processes, and community services linkages.[66] In 
general, specialized tertiary care ED's lack effective linkages to outpatient geriatric services, particularly when contrasted with the least-specialized community hospitals.[67] We distinguish two stylistic approaches to caring for geriatric emergencies: the geriatricfriendly $E D$ versus the geriatric-specific ED. Whereas all general adult ED's should aspire to become geriatric-friendly, the geriatric-specific ED only manages older adults. Currently, very few geriatric-specific ED's exist and most are within hospitals that also have a general adult ED, but they are geographically distinct with separate staffing, protocols, and objectives. Most healthcare systems lack the resources to build a geriatric-specific ED. In contrast, the geriatric-friendly EDs can be achieved in most settings and is the baseline level of geriatric care to which all adult ED's should aspire. A quality assessment tool for the geriatric-friendly ED has been developed and incorporates three subscales: screening/ assessment, discharge planning, and community services.[68] Although this instrument awaits validation, quality assessment tools for the geriatric-friendly ED will be essential for clinicians, managers, administrators, and payers to evaluate the merits of this concept.

The attributes of effective ED-based geriatric case management include an evidence-based practice model, nursing clinical involvement and leadership, high-risk screening protocols, focused geriatric assessments, the initiation of care and disposition planning in the ED, interprofessional and capacity-building work practices, post-ED discharge follow-up, and established quality improvement processes.[69] Clinical research in alternative ED management models which fails to demonstrate a clinically significant effect usually lack attention to more than one of these domains.[69, 70] In particular, whether the hospital environment is rural or urban, academic or community, engaging nurses in protocol development and case management is essential as demonstrated by the Regional Geriatric Programs of Ontario.[12]

Modification of the general adult ED towards a more geriatric-friendly ED that simultaneously yields optimal outcomes while minimizing resource consumption will need to incorporate focused staff education, pragmatic and evidence based screening services, simple infrastructural considerations that accommodate the physiological changes of aging, and readily available access to geriatricians. [Table 1] Educational priorities for physicians and nurses to improve the care of older adults have been identified: recognition of atypical disease presentation; trauma assessment principles; recognition of cognitive decline; pain management alternatives; transition of care principles; and the contribution of comorbid illnesses to both disease presentation and effective management strategies.[14] In 2011 the American College of Emergency Physicians' (ACEP) and Society for Academic Emergency Medicine (SAEM) Geriatric Sections produced and disseminated contemporary educational modules for many of these core competencies [Table 2].[71]

Universal screening occurs when asymptomatic individuals are evaluated for a condition. Case finding refers to the screening of a subset of patients based on the presence of risk factors. EM leaders have long advocated for both universal screening and case finding programs for geriatric syndromes like cognitive dysfunction, fall risk and frailty.[24, 72-74] At least two barriers obstruct the implementation of geriatric syndrome screening. First, very few appropriately brief, pragmatic ED screening instruments have been validated for these geriatric syndromes.[36, 75] Research continues to identify screening instruments for dementia,[76-78] fall risk,[79, 80] and functional decline, [81-83] but these instruments have yet to be validated in other settings and important geriatric syndromes like frailty and delirium await instrument validation in the ED. [36, 75] As a result, reviews and guidelines for ED management of geriatric syndromes like dementia are often extrapolated from nonED settings.[84] 
The second barrier is daily ED crowding and ongoing nursing shortages, which limit the time available for providers to conduct screening. One alternative management strategy is the "Geriatric Technician" (GT), an individual who is neither a nurse nor a physician with the sole responsibility of assessing elderly ED patients for geriatric syndromes using simple, reliable, and valid screening instruments. The GT workforce might consist of volunteers, students, or retirees. In one busy tertiary academic medical center EM nurses and physicians recognized the potential for the GT model to promote patient safety and improve overall clinical care without reducing ED operational flow.[85]

Changes in infrastructure appropriate for a geriatric-friendly ED overlap with those described for geriatric-specific EDs, but are simpler to implement without a geographically distinct site of care or expensive reconstruction. Simple alterations to the structure of the ED that promote a geriatric-friendly milieu include an easy chair in addition to or in place of the traditional hospital bed. Wilber et al demonstrated that in appropriate geriatric patients the easy chair was preferred with improved patient comfort and satisfaction scores and without any adverse events noted.[86] Another easy alteration that all ED's can implement is to increase the font of discharge instructions and prescriptions to accommodate the visually impaired.

Despite focused education of providers regarding geriatric care, ample screening mechanisms, and pragmatic infrastructural modifications, some elderly patient's diagnosis and short-term prognosis remain poorly defined at the end of an ED evaluation. Since current inpatient funding models, which rely on diagnoses to request compensation, discourage admission of these individuals, alternative rapid access consult systems provide a means to increase the likelihood that patient outcomes do not suffer from payers' policies. One approach to this problem is the mobile Acute Care for the Elderly (ACE) team. Whereas the traditional ACE unit is solely an inpatient site, the mobile ACE team brings the medical expertise of the unit to the ED to conduct comprehensive geriatric assessment screening,[87-89] caregiver and patient psychosocial needs assessment, and ensure access to outpatient resources based upon the results of their formal assessment.[36] Some settings have used hospitalists in the ED or hospital rather than geriatricians to staff the ACE unit. $[90,91]$

The geriatric-specific ED would incorporate all of the principles from the geriatric-friendly ED, but staff a geographically distinct ED for senior adults with nurses, physicians, social workers, and case coordinators specially trained to care for this population. This focus on geriatric adults permits an infrastructure that is completely modified for the older adult. The infrastructure includes appropriate lighting to optimize visual acuity while minimizing nocturnal delirium or other confusional states, handrails in hallways and bathrooms, protocols for pain and agitation management and fall prevention, slip-proof flooring, palliative care, and multidisciplinary care services with geriatric expertise that maintain continuity of care for admitted patients.

\section{Geriatric Emergency Care Beyond the Emergency Department}

Acute care for older adults does not end in the ED. For older adults with severe illness and injury, coordination of ED and inpatient care can improve the transfer of patient information, ensure that key interventions are initiated early and are continued after the patient leaves the ED, and ensure that patient care preferences are communicated to all providers. In contrast, failure to coordinate ED and inpatient care has the potential to prolong time in the ED lengths of stay and lead to frustration on the parts of patients, families, and providers. Trauma and delirium are two particular conditions in which coordination with inpatient specialists is likely to be of particular value. 
In the case of trauma, care at a trauma center for adults age 80 and older and activation of a trauma team for patients age 70 and older with an Injury Severity Score of 15 or more have each been associated with improved outcomes as compared to usual care.[92, 93] Thus, for older adults with serious injuries, early care by the trauma team is appropriate. Aggressive treatment in elderly trauma patients has been examined in observational studies, with most studies pointing to the value of intensive early treatment for older adults with lifethreatening injuries.[94-96] These studies also show that, as with other conditions in older adults, functional status and comorbidities are stronger predictors of outcomes from a given injury than age.

Like trauma, delirium is also a common and potentially life-threatening condition in older adults and likely to benefit from early initiation of specific therapies.[97, 98] Unfortunately, delirium is under-diagnosed in older ED patients.[99-103] As a result, any efforts to improve outcomes for ED patients with delirium must first ensure the early and accurate identification of delirious patients. Once identified, the goals of delirium care are to treat underlying causes while mitigating symptoms with a minimum of physical and chemical restraints. As compared with delayed management, early care of older adults with hyperactive delirium by geriatricians and psychogeriatricians have demonstrated improved outcomes.[104] Specifically, early interventions for hyperactive delirium in patients admitted from the ED reduce the need for physical (44\% vs. 63\%) or chemical (49\% vs. $76 \%$ ) restraint, reduced hospital length of stay (17 days vs. 25 days), reduced the duration of delirium (11 days versus 22 days), and lowered fall rates.

Once delirium is recognized, emergency providers should initiate delirium treatment in the ED. Key components of a comprehensive approach to treating delirium have been described: orientation; non-pharmacologic sleep aids; early mobilization; visual aids; hearing aids; and the prevention of dehydration.[105] Furthermore, communicating this diagnosis to the inpatient team and developing methods for continuing delirium treatment in the hospital is likely to be beneficial. Inpatient care by a multidisciplinary team led by a geriatrician with an emphasis on avoiding potential harmful interventions (e.g. Foley catheters, bed rest, some medications) has been associated with a greater improvement in physical function over usual care.[106, 107] This inpatient model evolved from the traditional Acute Care for the Elderly (ACE) unit to designate one area of the ACE unit the "delirium room" that is situated to permit continuous nurse monitoring with the intent to minimize delirium-related morbidity. The "delirium room" concept has been replicated in other inpatient settings and is costeffective, but opponents debate whether an ED-based observation unit for suspected delirium would be ethical, cost-effective, and utilized appropriately.[108, 109] Trials continue exploring the effect of the "delirium room" on patient outcomes.[110, 111]

\section{The Hospital at Home ${ }^{\circledR}$ Model}

For admitted patients of all ages, ED boarding times continue to increase, a trend likely to increase as baby-boomers become octogenarians.[112] Thought leaders, patient safety experts, and policy makers urge proactive and creative solutions to the challenge of ED boarding.[113] In addition, hospital care itself can be a health risk for geriatric adults with iatrogenic events such as functional decline, pressure sores, falls, and delirium commonly reported.[114] Alternatives to traditional inpatient management models exist and early trials have been promising. The "admission avoidance" Hospital at Home ${ }^{\circledR}$ model carefully selects a subset of geriatric patients for whom ED personnel deem hospital admission appropriate and who meet explicit criteria (Table 3)[115] for a few diagnoses including chronic obstructive pulmonary disease exacerbations, cellulitis, or pneumonia. The difference is that rather than being transferred to the hospital ward, these patients go home with an inpatient-like management plan. 
Hospital at Home ${ }^{\circledR}$ care includes telemetry, and at least 12-hours of nursing care and one physician home visit each day. One meta-analysis of five randomized trials including 844 patients demonstrated improved six month mortality (adjusted hazards ratio $0.62,95 \%$ confidence interval $0.45-0.87$ ) for the Hospital at Home ${ }^{\circledR}$ model.[116] Additionally, family members report less stress with Hospital at Home ${ }^{\circledR}$ management and healthcare providers view it as both viable and acceptable.[117, 118] In Australia this model has been sustainable over 7-years and less than 5\% fail the home care model by requiring transfer back to the hospital.[119] In the US the Hospital at Home ${ }^{\circledR}$ model was developed by Johns Hopkins and has been slow to disseminate.[120] The barriers to wider-spread implementation of this model in the US include an insufficient understanding of healthcare system adoption and infrastructural alteration costs, as well as the contradictory fee-for-service payment system that provides little incentive for hospital to adopt less expensive alternatives to admission. [121] However, in an era of increasingly constrained healthcare budgets, policy-makers are beginning to note that Hospital at Home ${ }^{\circledR}$ care is consistently less costly than traditional hospital management and is preferred by patients.[122]

\section{Conclusions}

Emergency care for an aging population represents a challenge and an opportunity for multidisciplinary management of acute health issues. Ample opportunity exists for the crossdisciplinary exchange of ideas through the American Geriatrics Society Section for Enhancing Geriatric Understanding and Expertise Among Surgical and Medical Specialists, [123] the SAEM Academy of Geriatric Emergency Medicine,[124] and the ACEP Geriatric Section.[125] A paradigm shift in the traditional ED management model and inpatient scenario will likely improve healthcare delivery for all age groups. However, the characteristics that define high-quality alternative management models for geriatric adults have yet to be delineated. In addition, the feasibility and financial sustainability of novel prehospital screening programs, geriatric friendly ED's, inpatient delirium rooms, and the Hospital at Home ${ }^{\circledR}$ model remain largely untested.[36] Nonetheless, these alternative management strategies provide a template for heterogeneous emergency care environments around the world to begin exploring more efficient pathways of care for a rapidly aging society.

\section{Acknowledgments}

Dr. Platts-Mills is supported by Award Number KL2 TR000084 and UL1 TR000083 from the National Center for Research Resources through the North Carolina Translational and Clinical Science Institute. The content is solely the responsibility of the authors and does not necessarily represent the official views of the National Center for Research Resources, the National Institutes of Health, or the North Carolina Translational and Clinical Science Institute.

\section{REFERENCES}

1. Roberts DC, McKay MP, Shaffer A. Increasing rates of emergency department visits for elderly patients in the United States, 1993 to 2003. Ann Emerg Med. 2008; 51(6):769-774. [PubMed: 18069088]

2. Banarjee, J.; Conroy, S.; O'Leary, V.; Rawstorne, S.; Wenman, J.; Walker, A.; Docherty, M.; Donovan, S.; Mukherjee, S.; Sturgess, I., et al. British Geriatrics Society. 2011. Quality care for older people with urgent and emergency care needs; p. 102

3. Fitzgerald, RT. The Future of Geriatric Care in Our Nation's Emergency Departments: Impact and Implications. 2008. American College of Emergency Physicians White Paper.

4. Fealy GM, Treacy M, Drennan J, Naughton C, Butler M, Lyons I. A profile of older emergency department attendees: findings from an Irish study. J Adv Nurs. 2012; 68(5):1003-1013. [PubMed: 21831130] 
5. Gruneir A, Silver MJ, Rochon PA. Emergency department use by older adults: a literature review on trends, appropriateness, and consequences of unmet health care needs. Med Care Res Rev. 2011; 68(2):131-155. [PubMed: 20829235]

6. Schumacher JG. Emergency Medicine and Older Adults: Continuing Challenges and Opportunities. Am J Emerg Med. 2005; 23:556-560. [PubMed: 16032631]

7. Schumacher JG, Deimling GT, Meldon SW, Woolard B. Older adults in the emergency department: predicting physicians' burden levels. J Emerg Med. 2006; 30(4):455-460. [PubMed: 16740465]

8. Hwang U, Morrison RS. The geriatric emergency department. J Am Geratr Soc. 2007; 55(11):18731876.

9. Samaras N, Chevalley T, Samaras D, Gold G. Older patients in the emergency department: a review. Ann Emerg Med. 2010; 56(3):261-269. [PubMed: 20619500]

10. Roethler C, Adelman T, Parsons V. Assessing emergency nurses' geriatric knowledge and perceptions of their geriatric care. J Emerg Nurs. 2011; 37(2):132-137. [PubMed: 21397125]

11. Sanders, AB.; Witzke, DB.; Jones, JS.; Richmond, K.; Kidd, P. Principles of care and application of the geriatric emergency care model. In: Sanders, AB., editor. Emergency Care of the Elder Person. Beverly-Cracom Publications; St. Louis, MO: 1996. p. 59-93.

12. Ryan D, Liu B, Awad M, Wong K. Improving older patients' experience in the emergency room: the senior-friendly emergency room. Aging Health. 2011; 7(6):901-909.

13. Schnitker L, Martin-Khan M, Beattie E, Gray L. Negative health outcomes and adverse events in older people attending emergency departments: A systematic review. Austalasian Emerg Nurs J. $2011 ; 14: 141-162$.

14. Hogan TM, Losman ED, Carpenter CR, Sauvigne K, Irmiter C, Emanuel L, Leipzeip RM. Development of geriatric competencies for emergency medicine residents using an expert consensus process. Acad Emerg Med. 2010; 17(3):316-324. [PubMed: 20370765]

15. Nemac M, Koller MT, Nickel CH, Maile S, Winterhalder C, Karrer C, Laifer G, Bingisser R. Patients presenting to the emergency department with non-specific complaints: the Basel Nonspecific Complaints (BANC) study. Acad Emerg Med. 2010; 17(3):284-292. [PubMed: 20370761]

16. Keim, SM.; Sanders, AB. Geriatric Emergency Department Use and Care. In: Meldon, SW.; Ma, OJ.; Woolard, R., editors. Geriatric Emergency Medicine. McGraw Hill; New York: 2004. p. 1-3.

17. Birnbaumer, DM. The Elder Patient. In: Marx, JA.; Hockberger, RS.; Walls, RM.; Adams, JG.; Barsan, WG.; Biros, MH.; Danzl, DF.; Gausche-Hill, M.; Ling, LJ.; Newton, EJ., editors. Rosen's Emergency Medicine: Concepts and Clinical Practice. 7th edn. Mosby Elsevier; Philadelphia: 2010. p. 2348-2352.

18. Hastings SN, George LK, Fillenbaum GG, Park RS, Burchett BM, Schmader KE. Does lack of social support lead to more ED visits for older adults? Am J Emerg Med. 2008; 26(4):454-461. [PubMed: 18410815]

19. Papaioannou ES, Räihä I, Kivelä SL. Self-neglect of the elderly. An overview. Eur J Gen Pract. 2012 in press.

20. Hohl CM, Dankoff J, Colacone A, Afilalo M. Polypharmacy, Adverse Drug-Related Events, and Potential Adverse Drug Interactions in Elderly Patients Presenting to an Emergency Department. Ann Emerg Med. 2001; 38(6):666-671. [PubMed: 11719747]

21. Hohl CM, Zed PJ, Brubacher JR, Abu-Laban RB, Loewen PS, Purssell RA. Do emergency physicians attribute drug-related emergency department visits to medication-related problems? Ann Emerg Med. 2010; 55(6):493-502. [PubMed: 20005010]

22. Baena MI, Faus MJ, Fajardo PC, Luque FM, Sierra F, Martinez-Olmos J, Cabrera A, FernandezLlimos F, Martinez-Martinez-F, Jimenez J, et al. Medicine-related problems resulting in emergency department visits. Eur J Clin Pharmacol. 2006; 62(5):387-393. [PubMed: 16604344]

23. Gill TM, Gahbauer EA, Murphy TE, Han L, Allore HG. Risk factors and precipitants of long-term disability in community mobility: a cohort study of older persons. Ann Intern Med. 2012; 156(2): 131-140. [PubMed: 22250144]

24. Sanders AB. Missed delirium in older emergency department patients: a quality-of-care problem. Ann Emerg Med. 2002; 39(3):338-341. [PubMed: 11867994] 
25. Dramé M, Novella JL, Lang PO, Somme D, Jovenin N, Lanièce I, Couturier P, Heitz D, Gauvain JB, Voisin T, et al. Derivation and validation of a mortality-risk index from a cohort of frail elderly patients hospitalised in medical wards via emergencies: the SAFES study. Eur J Epidemiol. 2008; 23(12):783-791. [PubMed: 18941907]

26. Gosch, M.; Joosten-Gstrein, B.; Heppner, HJ.; Lechleitner, M. Gerontology. 2012. Hyponatremia in Geriatric Inhospital Patients: Effects on Results of a Comprehensive Geriatric Assessment. in press

27. Wiegand JV, Gerson LW. Preventive care in the emergency department: should emergency departments institute a falls prevention program for elder patients? A systematic review. Acad Emerg Med. 2001; 8:823-826. [PubMed: 11483459]

28. Paniagua MA, Malphurs JE, Phelan EA. Older patients presenting to a county hospital ED after a fall: missed opportunities for prevention. Am J Emerg Med. 2006; 24(4):413-417. [PubMed: 16787797]

29. Shah MN, Bazarian JJ, Lerner EB, Fairbanks RJ, Barker WH, Auinger P, Friedman B. The epidemiology of emergency medical services use by older adults: an analysis of the National Hospital Ambulatory Medical Care Survey. Acad Emerg Med. 2007; 14(5):441-447. [PubMed: 17456555]

30. Platts-Mills TF, Leacock B, Cabañas JG, Shofer FS, McLean SA. Emergency medical services use by the elderly: analysis of a statewide database. Prehosp Emerg Care. 2010; 14(3):329-333. [PubMed: 20507220]

31. Geriatric Education for Emergency Medical Services. http://www.gemssite.com/

32. Shah MN, Rajasekaran K, Sheahan WD, Wimbush T, Karuza J. The effect of the geriatrics education for emergency medical services training program in a rural community. $\mathrm{J}$ Am Geriatr Soc. 2008; 56(6):1134-1139. [PubMed: 18482304]

33. Shah MN, Swanson PA, Nobay F, Peterson LK, Caprio TV, Karuza J. A novel internet-based geriatric education program for emergency medical services providers. J Am Geriatr Soc. 2012; 60(9):1749-1754. [PubMed: 22906239]

34. Shah MN, Clarkson L, Lerner EB, Fairbanks RJ, McCann R, Schneider SM. An emergency medical services program to promote the health of older adults. J Am Geriatr Soc. 2006; 54(6): 956-962. [PubMed: 16776792]

35. Lerner EB, Fernandez AR, Shah MN. Do emergency medical services professionals think they should participate in disease prevention? Prehosp Emerg Care. 2009; 13(1):64-70. [PubMed: 19145527]

36. Carpenter CR, Shah MN, Hustey FM, Heard K, Miller DK. High yield research opportunities in geriatric emergency medicine research: prehospital care, delirium, adverse drug events, and falls. J Gerontol Med Sci. 2011; 66(7):775-783.

37. Glickman SW, Shofer FS, Wu MC, Scholer MJ, Ndubuizu A, Peterson ED, Granger CB, Cairns $\mathrm{CB}$, Glickman LT. Development and validation of a prioritization rule for obtaining an immediate 12-lead electrocardiogram in the emergency department to identify ST-elevation myocardial infarction. Am Heart J. 2012; 163(3):372-382. [PubMed: 22424007]

38. Kothari RU, Pancioli A, Liu T, Brott T, Broderick J. Cincinnati Prehospital Stroke Scale: reproducibility and validity. Ann Emerg Med. 1999; 33(4):373-378. [PubMed: 10092713]

39. Katzan IL, Furlan AJ, Lloyd LE, Frank JI, Harper DL, Hinchey JA, Hammel JP, Qu A, Sila CA. Use of tissue-type plasminogen activator for acute ischemic stroke: the Cleveland area experience. JAMA. 2000; 283(9):1151-1158. [PubMed: 10703777]

40. Hoffman JR, Schriger DL. A graphic reanalysis of the NINDS Trial. Ann Emerg Med. 2009; 54(3):329-336. [PubMed: 19464756]

41. Gomez-Choco M, Obach V, Urra X, Amaro S, Cervera A, Vargas M, Chamorro A. The response to IV rt-PA in very old stroke patients. European journal of neurology : the official journal of the European Federation of Neurological Societies. 2008; 15(3):253-256. [PubMed: 18190509]

42. Mishra NK, Ahmed N, Andersen G, Egido JA, Lindsberg PJ, Ringleb PA, Wahlgren NG, Lees KR. Thrombolysis in very elderly people: controlled comparison of SITS International Stroke Thrombolysis Registry and Virtual International Stroke Trials Archive. BMJ. 2010; 341:c6046. [PubMed: 21098614] 
43. Boulouis G, Dumont F, Cordonnier C, Bodenant M, Leys D, Henon H. Intravenous thrombolysis for acute cerebral ischaemia in old stroke patients $>/=80$ years of age. Journal of neurology. 2011; 259(7):1461-1467. [PubMed: 22183776]

44. Dirks M, Koudstaal PJ, Dippel DW, Niessen LW, van Wijngaarden JD, Franke CL, van Oostenbrugge RJ. Effectiveness of thrombolysis with intravenous alteplase for acute ischemic stroke in older adults. J Am Geriatr Soc. 2011; 59(11):2169-2171. [PubMed: 22098036]

45. Sung PS, Chen CH, Hsieh HC, Fang CW, Hsieh CY, Sun YT, Hwang WJ. Outcome of acute ischemic stroke in very elderly patients: is intravenous thrombolysis beneficial? European neurology. 2011; 66(2):110-116. [PubMed: 21849787]

46. Zacharatos H, Hassan AE, Vazquez G, Hussein HM, Rodriguez GJ, Suri MF, Lakshminarayan K, Ezzeddine MA, Qureshi AI. Comparison of acute nonthrombolytic and thrombolytic treatments in ischemic stroke patients 80 years or older. Am J Emerg Med. 2012; 30(1):158-164. [PubMed: 21247724]

47. Wardlaw JM, Murray V, Berge E, del Zoppo G, Sandercock P, Lindley RL, Cohen G. Recombinant tissue plasminogen activator for acute ischaemic stroke: an updated systematic review and meta-analysis. Lancet. 2012; 379(9834):2364-2372. [PubMed: 22632907]

48. Phillips S, Rond PC, Kelly SM, Swarrtz PD. The failure of triage criteria to identify geriatric patients with trauma: results from the Florida Trauma Triage Study. J Trauma. 1996; 40(2):278283. [PubMed: 8637079]

49. Chang DC, Bass RR, Cornwell EE, Mackenzie EJ. Undertriage of elderly trauma patients to statedesignated trauma centers. Arch Surg. 2008; 143(8):776-781. [PubMed: 18711038]

50. Platts-Mills TF, Travers D, Biese K, McCall B, Kizer S, LaMantia MA, Busby-Whitehead J, Cairns CB. Accuracy of the Emergency Severity Index triage instrument for identifying elder emergency department patients receiving an immediate life-saving intervention. Acad Emerg Med. 2010; 17(3):238-243. [PubMed: 20370755]

51. Takahashi PY, Pecina JL, Upatising B, Chaudhry R, Shah ND, Van Houten H, Cha S, Croghan I, Naessens JM, Hanson GJ. A randomized controlled trial of telemonitoring in older adults with multiple health issues to prevent hospitalizations and emergency department visits. Arch Intern Med. 2012; 172(10):773-779. [PubMed: 22507696]

52. McCusker CM, Verdon J. Do geriatric interventions reduce emergency department visits? A systematic review. J Gerontol A Biol Sci Med Sci. 2006; 61(1):53-62. [PubMed: 16456194]

53. Coleman EA, Eilertsen TB, Kramer AM, Maqid DJ, Beck A, Conner D. Reducing emergency visits in older adults with chronic illness. A randomized, controlled trial of group visits. Eff Clin Pract. 2001; 4(2):49-57. [PubMed: 11329985]

54. Cohen RA, Bloom B, Simpson G, Parsons PE. Access to health care. Part 3: Older adults. Vital and Health Statistics Series 10, Data from the National Health Survey. 1997; (198):1-32.

55. Kovner CT, Mezey M, Harrington C. Who cares for older adults? Workforce implications of an aging society. Health Aff. 2002; 21(5):78-89.

56. Shah MN, Caprio TV, Swanson P, Rajasekaran K, Ellison JH, Smith K, Frame P, Cypher P, Karuza J, Katz P. A novel emergency medical services-based program to identify and assist older adults in a rural community. J Am Geriatr Soc. 2010; 58(11):2205-2211. [PubMed: 21054301]

57. Gerson LW, Schelble DT, Wilson JE. Using paramedics to identify at-risk elderly. Ann Emerg Med. 1992; 21(6):688-691. [PubMed: 1590608]

58. Weiss SJ, Chong R, Ong M, Ernst AA, Balash M. Emergency medical services screening of elderly falls in the home. Prehosp Emerg Care. 2003; 7(1):79-84. [PubMed: 12540148]

59. Kue R, Ramstrom E, Weisberg S, Restuccia M. Evaluation of an emergency medical servicesbased social services referral program for elderly patients. Prehosp Emerg Care. 2009; 13(3):273279. [PubMed: 19499461]

60. Comans TA, Currin ML, Quinn J, Tippett V, Rogers A, Haines TP. Problems with a great idea: referral by prehospital emergency services to a community-based falls-prevention service. Inj Prev. 2012 in press.

61. Lowton K, Laybourne AH, Whiting DG, Martin FC. Can Fire and Rescue Services and the National Health Service work together to improve the safety and wellbeing of vulnerable older 
people? Design of a proof of concept study. BMC Health Serv Res. 2010; 10:327. [PubMed: 21129185]

62. Snooks H, Cheung WY, Close J, Dale J, Gaze S, Humphreys I, Lyons R, Masons S, Merali Y, Peconi J, et al. Support and Assessment for Fall Emergency Referrals (SAFER 1) trial protocol. Computerised on-scene decision support for emergency ambulance staff to assess and plan care for older people who have fallen: evaluation of costs and benefits using a pragmatic cluster randomised trial. BMC Emerg Med. 2010; 10:2. [PubMed: 20102616]

63. Cohen RA, Bloom B, Simpson G, Parsons PE. Access to health care. Part 3: Older adults. Vital Health Stat 10. 1997; (198):1-32.

64. Halter M, Vernon S, Snooks H, Porter A, Close J, Moore F, Porsz S. Complexity of the decisionmaking process of ambulance staff for assessment and referral of older people who have fallen: a qualitative study. Emerg Med J. 2011; 28(1):44-50. [PubMed: 20472704]

65. Snooks H, Hutchings H, Russell I, Stewart-Brown S, Williams J, Seagrove A. Bureaucracy stifles medical research in Britain: a tale of three trials. BMC Med Res Methodol. 2012; 12(1):122. [PubMed: 22898336]

66. Borges-Da Silva R, McCusker J, Roberge D, Ciampi A, Vadeboncoeur A, Levesque JF, Belzile E. Classification of emergency departments according to their services for community-dwelling seniors. Acad Emerg Med. 2012; 19(5):552-561. [PubMed: 22594359]

67. McCusker J, Roberge D, Ciampi A, Da Silva RB, Vadeboncoeur A, Larouche D, Levesque JF, Belzile E. Outcomes of community-dwelling seniors vary by type of emergency department. Acad Emerg Med. 2012; 19(3):304-312. [PubMed: 22435863]

68. McCusker J, Verdon J, Vadeboncoeur A, Lévesque JF, Sinha SK, Kim KY, Belzile E. The elderfriendly emergency department assessment tool: development of a quality assessment tool for emergency department-based geriatric care. J Am Geriatr Soc. 2012; 60(8):1534-1539. [PubMed: 22860623]

69. Sinha SK, Bessman ES, Flomenbaum N, Leff B. A systematic review and qualitative analysis to inform the development of a new emergency department-based geriatric case management model. Ann Emerg Med. 2011; 57(6):672-682. [PubMed: 21621093]

70. Fealy GM, McCarron M, O'Neill D, McCallion P, Clarke M, Small V, O'Driscoll A, Cullen A. Effectiveness of gerontologically informed nursing assessment and referral interventions for older persons attending the emergency department: systematic review. J Adv Nurs. 2009; 65(5):934935. [PubMed: 19399966]

71. Clinical \& Practice Management: Geriatric Videos. http://www.acep.org/Clinical---PracticeManagement/Geriatric-Videos/

72. Gerson LW, Counsell SR, Fontanarosa PB, Smucker WD. Case finding for cognitive impairment in elderly emergency department patients. Ann Emerg Med. 1994; 23(4):813-817. [PubMed: 8161052]

73. Terrell KM, Hustey FM, Hwang U, Gerson LW, Wenger NS. Quality indicators for geriatric emergency care. Acad Emerg Med. 2009; 16(5):441-449. [PubMed: 19344452]

74. Carpenter CR, Heard K, Wilber ST, Ginde AA, Stiffler K, Gerson LW, Wenger NS, Miller DK. Research priorities for high-quality geriatric emergency care: medication management, screening, and prevention and functional assessment. Acad Emerg Med. 2011; 18(6):644-654. [PubMed: 21676064]

75. Carpenter, CR.; Gerson, L. Geriatric emergency medicine. In: LoCicero, J.; Rosenthal, RA.; Katic, M.; Pompei, P., editors. A Supplment to New Frontiers in Geriatrics Research: An Agenda for Surgical and Related Medical Specialties. 2nd edn. The American Geriatrics Society; New York: 2008. p. 45-71.

76. Wilber ST, Carpenter CR, Hustey FM. The six-item screener to detect cognitive impairment in older emergency department patients. Acad Emerg Med. 2008; 15(7):613-616. [PubMed: 18691212]

77. Carpenter CR, DesPain B, Keeling TK, Shah M, Rothenberger M. The Six-Item Screener and AD8 for the detection of cognitive impairment in geriatric emergency department patients. Ann Emerg Med. 2011; 57(6):653-661. [PubMed: 20855129] 
78. Carpenter CR, Bassett ER, Fischer GM, Shirshekan J, Galvin JE, Morris JC. Four sensitive screening tools to detect cognitive impairment in geriatric emergency department patients: Brief Alzheimer's Screen, Short Blessed Test, Ottawa3DY, and the Caregiver Administered AD8. Acad Emerg Med. 2011; 18(4):374-384. [PubMed: 21496140]

79. Close JC, Hooper R, Glucksman E, Jackson SH, Swift CG. Predictors of falls in a high risk population: results from the prevention of falls in the elderly trial (PROFET). Emerg Med J. 2003; 20(5):421-425. [PubMed: 12954679]

80. Carpenter CR, Scheatzle MD, D'Antonio JA, Ricci PT, Coben JH. Identification of fall risk factors in older adult emergency department patients. Acad Emerg Med. 2009; 16(3):211-219. [PubMed: 19281493]

81. McCusker J, Bellavance F, Cardin S, Trepanier S, Verdon J, Ardman O. Detection of older people at increased risk of adverse health outcomes after an emergency visit: the ISAR screening tool. J Am Geriatr Soc. 1999; 47(10):1229-1237. [PubMed: 10522957]

82. Meldon SW, Mion LC, Palmer RM, Drew BL, Connor JT, Lewicki LJ, Bass DM, Emerman C. A Brief Risk-Stratification Tool to Predict Repeat Emergency Department Visits and Hospitalizations in Older Patients Discharged from the Emergency Department. Acad Emerg Med. 2003; 10:224-232. [PubMed: 12615588]

83. Boyd M, Koziol-McLain J, Yates K, Kerse N, McLean C, Pilcher C, Robb G. Emergency department case-finding for high-risk older adults: the Brief Risk Identification for Geriatric Health Tool (BRIGHT). Acad Emerg Med. 2008; 15(7):598-606. [PubMed: 18691210]

84. Clevenger CK, Chu TA, Yang Z, Hepburn KW. Clinical care of persons with dementia in the emergency department: a review of the literature and agenda for research. J Am Geriatr Soc. 2012; 60(9):1742-1748. [PubMed: 22985144]

85. Carpenter CR, Griffey RT, Stark S, Coopersmith CM, Gage BF. Physician and Nurse Acceptance of Geriatric Technicians to Screen for Geriatric Syndromes in the Emergency Department. West J Emerg Med. 2011; 12(4):489-495. [PubMed: 22224145]

86. Wilber ST, Burger B, Gerson LW, Blanda M. Reclining Chairs Reduce Pain from Gurneys in Older Emergency Department Patients: A Randomized Controlled Trial. Acad EM. 2005; 12:119123.

87. Conroy SP, Stevens T, Parker SG, Gladman JR. A systematic review of comprehensive geriatric assessment to improve outcomes for frail older people being rapidly discharged from acute hospital: 'interface geriatrics'. Age Ageing. 2011; 40(4):436-443. [PubMed: 21616954]

88. Ellis G, Whitehead M, O'Neill D, Langhorne P, Robinson D. Comprehensive geriatric assessment for older adults admitted to hospital. Cochrane Database of Systematic Reviews. 2011; 7:CD006211. [PubMed: 21735403]

89. Arendts G, Fitzhardinge S, Pronk K, Donaldson M, Hutton M, Nagree Y. The impact of early emergency department allied health intervention on admission rates in older people: a nonrandomized clinical study. BMC Geriatr. 2012; 12:8. [PubMed: 22429561]

90. Chadaga SR, Shockley L, Keniston A, Klock NE, Van Dyke S, Davis Q, Chu ES. Hospitalist-Led medicine emergency department team: Associations with throughput, timeliness of patient care, and satisfaction. J Hosp Med. 2012 in press.

91. Wald HL, Glasheen JJ, Guerrasio J, Youngwerth JM, Cumbler EU. Evaluation of a hospitalist-run acute care for the elderly service. J Hosp Med. 2011; 6(6):313-321. [PubMed: 21834112]

92. Demetriades D, Karaiskakis M, Velmahos GC, Alo K, Newton E, Murray JA, Asensio JA, Belzberg H, Berne TV, Shoemaker W. Effect on Outcome of Early Intensive Management of Geriatric Trauma Patients. Brit J Surg. 2002; 89:1319-1322. [PubMed: 12296905]

93. Meldon SW, Reilly M, Drew BL, Mancuso C, Fallon W. Trauma in the very elderly: a communitybased study of outcomes at trauma and nontrauma centers. J Trauma. 2002; 52(1):79-84. [PubMed: 11791055]

94. Shabot MM, Johnson CL. Outcome from critical care in the "oldest old" trauma patients. J Trauma. 1995; 39(2):254-259. [PubMed: 7674393]

95. Battistella FD, Din AM, Perez L. Trauma patients 75 years and older: long-term follow-up results justify aggressive management. J Trauma. 1998; 44(4):618-623. [PubMed: 9555832] 
96. Richmond TS, Kauder D, Strumpf N, Meredith T. Characteristics and Outcomes of Serious Trauma Injury in Older Adults. J Am Geriatr Soc. 2002; 50(2):215-222. [PubMed: 12028201]

97. Kakuma R, Galbaud du Fort G, Arsenault L, Perrault A, Platt RW, Monette J, Moride Y, Wolfson C. Delirium in Older Emergency Department Patients Discharged Home: Effect on Survival. J Am Geriatr Soc. 2003; 51(4):443-450. [PubMed: 12657062]

98. Han JH, Shintani A, Eden S, Morandi A, Solberg LM, Schnelle J, Dittus RS, Storrow AB, Ely EW. Delirium in the emergency department: an independent predictor of death within 6 months. Ann Emerg Med. 2010; 56(3):244-252. [PubMed: 20363527]

99. Lewis LM, Miller DK, Morley JE, Nork MJ, Lasater LC. Unrecognized delirium in ED geriatric patients. Am J Emerg Med. 1995; 13(2):142-145. [PubMed: 7893295]

100. Naughton BJ, Moran MB, Kadah H, Heman-Ackah Y, Longano J. Delirium and other cognitive impairment in older adults in an emergency department. Ann Emerg Med. 1995; 25(6):751-755. [PubMed: 7755195]

101. Elie M, Rousseau F, Cole M, Primeau F, McCusker J, Bellavance F. Prevalence and detection of delirium in elderly emergency department patients. CMAJ. 2000; 163(8):977-981. [PubMed: 11068569]

102. Hustey FM, Meldon SW. The prevalence and documentation of impaired mental status in elderly emergency department patients. Ann Emerg Med. 2002; 39(3):248-253. [PubMed: 11867976]

103. Han JH, Zimmerman EE, Cutler N, Schnelle J, Morandi A, Dittus RS, Storrow AB, Ely EW. Delirium in older emergency department patients: recognition, risk factors, and psychomotor subtypes. Acad Emerg Med. 2009; 16(3):193-200. [PubMed: 19154565]

104. Lu JH, Chan DK, O'Rourke F, Ong B, Shen Q, Reutens S, Ko A. Management and outcomes of delirious patients with hyperactive symptoms in a secured behavioral unit jointly used by geriatricians and pyschogeriatricians. Arch Gerontol Geeriatr. 2011; 52(1):66-70.

105. Inouye SK, Bogardus ST, Charpentier PA, Leo-Summers L, Acampora D, Holford TR, Cooney LM. A multicomponent intervention to prevent delirium in hospitalized older patients. N Engl J Med. 1999; 340(9):669-676. [PubMed: 10053175]

106. Flaherty JH, Steele DK, Chibnall JT, Vasudevan VN, Bassil N, Vegi S. An ACE unit with a delirium room may improve function and equalize length of stay among older delirious medical inpatients. J Gerontol A Biol Sci Med Sci. 2010; 65(12):1387-1392. [PubMed: 20679073]

107. Flaherty JH, Little MO. Matching the environment to patients with delirium: lessons learned from the delirium room, a restraint-free environment for older hospitalized adults with delirium. J Am Geriatr Soc. 2011; 59(Suppl 2):S295-S300. [PubMed: 22091576]

108. Wong Tin Niam DM, Geddes JA, Inderjeeth CA. Delirium unit: our experience. Australas J Ageing. 2009; 28(4):206-210. [PubMed: 19951343]

109. Modawal A. Model and systems of geriatric care: "delirium rooms"--but where and at what cost? J Am Geriatr Soc. 2004; 52(6):1023. [PubMed: 15161475]

110. Chong MS, Chan MP, Kang J, Han HC, Ding YY, Tan TL. A new model of delirium care in the acute geriatric setting: geriatric monitoring unit. BMC Geriatr. 2011; 11:41. [PubMed: 21838912]

111. Harwood RH, Goldberg SE, Whittamore KH, Russell C, Gladman JR, Jones RG, Porock D, Lewis SA, Bradshaw LE, Elliot RA, et al. Evaluation of a Medical and Mental Health Unit compared with standard care for older people whose emergency admission to an acute general hospital is complicated by concurrent 'confusion': a controlled clinical trial. Acronym: TEAM: Trial of an Elderly Acute care Medical and mental health unit. Trials. 2011; 12:123. [PubMed: 21569471]

112. Pines JM, Hilton JA, Weber EJ, Alkemade AJ, Al Shabanah H, Anderson PD, Bernhard M, Bertini A, Gries A, Ferrandiz S, et al. International perspectives on emergency department crowding. Acad Emerg Med. 2011; 18(12):1358-1370. [PubMed: 22168200]

113. Rabin E, Kocher K, McClelland M, Pines JM, Hwang U, Rathley N, Asplin B, Trueger NS, Weber EJ. Solutions to emergency department 'boarding' and crowding are underused and may need to be legislated. Health Aff. 2012; 31(8):1757-1766.

114. Creditor MD. Hazards of hospitalization of the elderly. Ann Intern Med. 1993; 118(3):219-223. [PubMed: 8417639] 
115. Leff B, Burton L, Bynum JW, Harper M, Greenough WB, Steinwachs D, Burton JR. Prospective evaluation of clinical criteria to select older persons with acute medical illness for care in a hypothetical home hospital. J Am Geriatr Soc. 1997; 45(9):1066-1073. [PubMed: 9288013]

116. Shepperd S, Doll H, Angus RM, Clarke MJ, Illiffe S, Kalra L, Ricauda NA, Tibaldi V, Wilson AD. Avoiding hospital admission through provision of hospital care at home: a systematic review and meta-analysis of individual patient data. CMAJ. 2009; 180(2):175-182. [PubMed: 19153394]

117. Leff B, Burton L, Mader SL, Naughton BJ, Burl J, Koehn D, Clark R, Greenough WB, Guido S, Steinwachs D, et al. Comparison of stress experienced by family members of patients treated in hospital at home with that of those receiving traditional acute hospital care. J Am Geriatr Soc. 2008; 56(1):117-123. [PubMed: 17979955]

118. Marsteller JA, Burton L, Mader SL, Naughton BJ, Burl J, Guido S, Greenough WB, Steinwachs D, Clark R, Leff B. Health care provider evaluation of a substitutive model of hospital at home. Med Care. 2009; 47(9):979-985. [PubMed: 19704355]

119. Montalto M, Lui B, Mullins A, Woodmason K. Medically-managed Hospital in the Home: 7 year study of mortality and unplanned interruption. Aust Health Rev. 2010; 34(3):269-275. [PubMed: 20797356]

120. Leff B, Burton L, Mader SL, Naughton B, Burl J, Inouye SK, Greenough WB, Guido S, Langston C, Frick KD, et al. Hospital at Home: Feasibility and Outcomes of a Program to Provide Hospital-Level Care at Home for Acutely Ill Older Patients. Ann Int Med. 2005; 143:798-808. [PubMed: 16330791]

121. Leff B. Defining and disseminating the hospital-at-home model. CMAJ. 2009; 180(2):156-157. [PubMed: 19153385]

122. Cryer L, Shannon SB, Van Amsterdam M, Leff B. Costs for 'hospital at home' patients were 19 percent lower, with equal or better outcomes compared to similar inpatients. Health Aff. 2012; 31(6):1237-1243.

123. Section for Enhancing Geriatric Understanding and Expertise Among Surgical and Medical Specialists. http://specialists.americangeriatrics.org/about.php

124. Academy of Geriatric Emergency Medicine. http://www.saem.org/academy-geriatric-emergencymedicine

125. Geriatric Emergency Medicine Section. http://www.acep.org/Content.aspx?id=25112 


\section{KEY POINTS}

1. Ensuring high quality and efficient emergency care for the growing number of older US adults will require the development of alternative management strategies for providing emergency care.

2. Prehospital emergency care for older adults may be improved through the development of new methods for the early detection of acute severe illness and injury in order to guide timely condition-specific treatment.

3. Prehospital providers may make an additional contribution to the health of older adults by conducting in-home assessments and referral of high-risk older adults.

4. Emergency department care may be improved through a team approach and through standardized screening procedures for important commonly over-looked conditions (e.g., delirium, dementia, depression, drug-related adverse effects, neglect/abuse).

5. For conditions with high mortality rates (e.g., trauma, delirium), improved coordination of care during the transition from the emergency department to the inpatient setting may improve outcomes. 


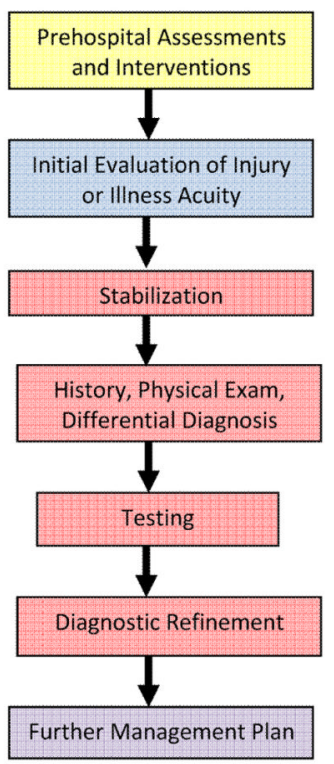

Settings Where Processes Occur

Yellow = Home, Clinic, Accident-Scene or Nursing Home Environment Blue $=$ Waiting Room or Triage station

Red $=E D$ patient room or hallway

Purple = Observation Unit, Inpatient or Outpatient Setting

Figure 1a.

Traditional EM Management Pathway*

*Adapted from [11] with permission. 

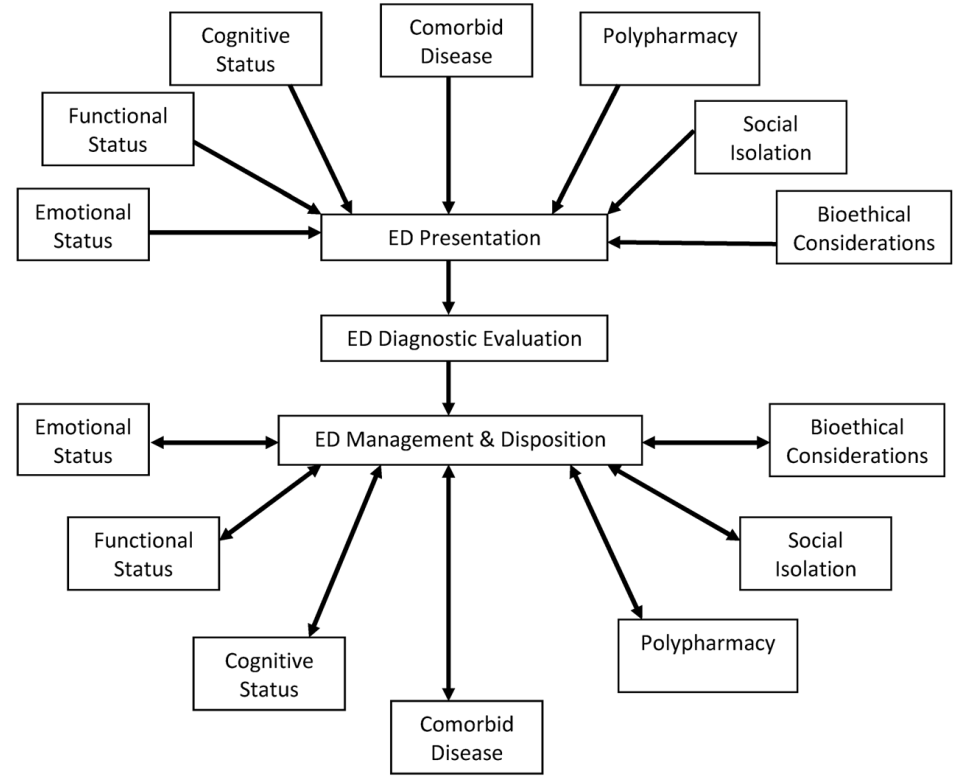

Figure 1b.

Geriatric Emergency Care Model*

*Adapted from [11] with permission. 


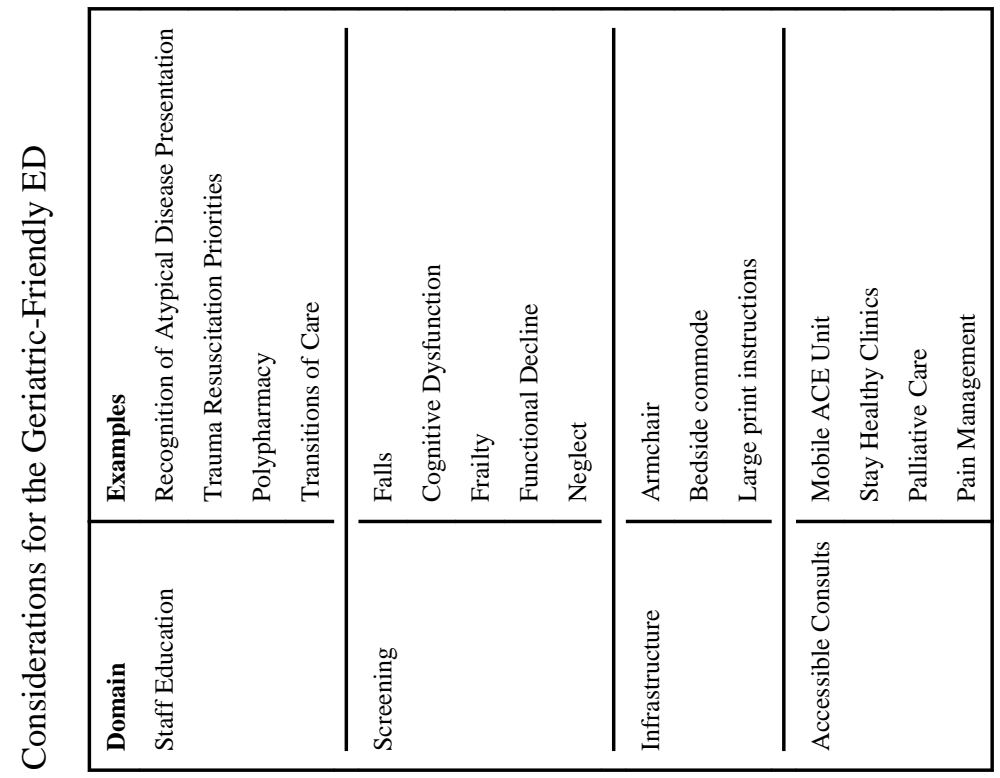

Clin Geriatr Med. Author manuscript; available in PMC 2014 February 01. 


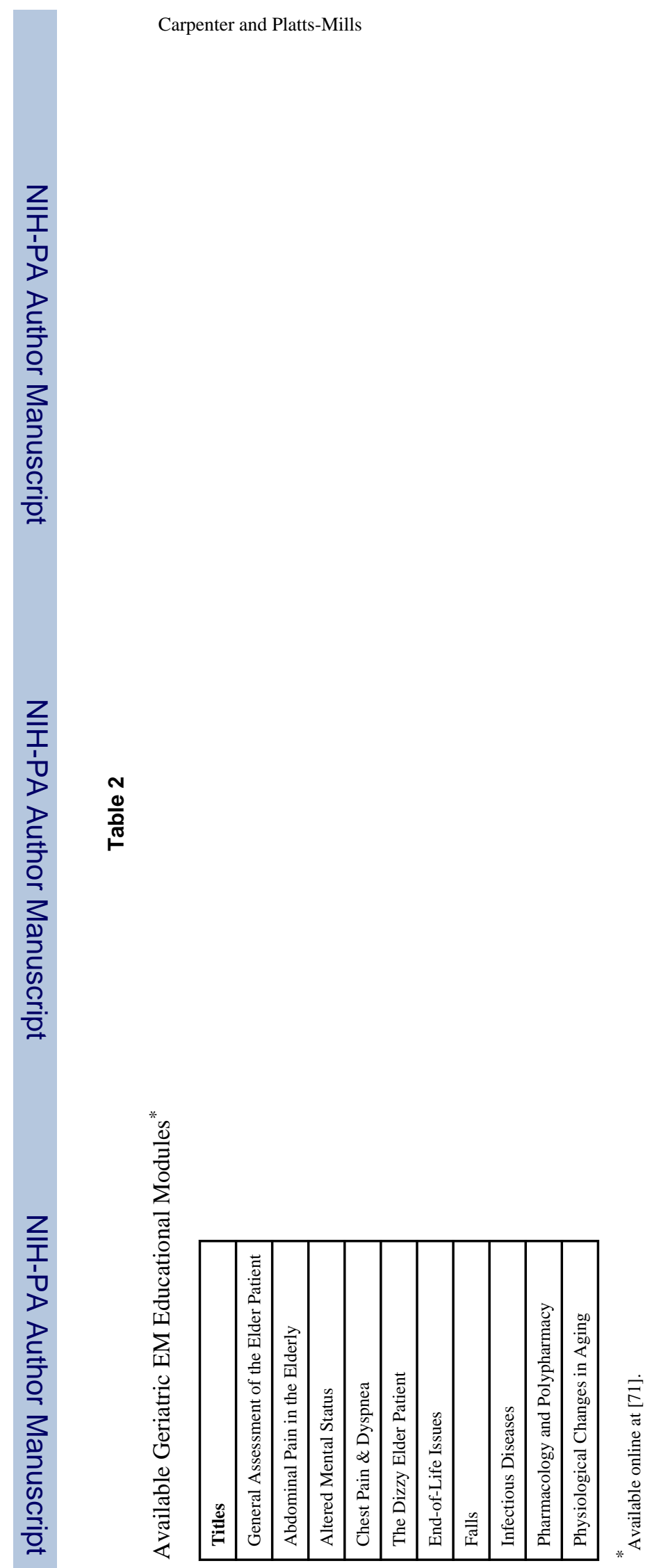

Clin Geriatr Med. Author manuscript; available in PMC 2014 February 01. 


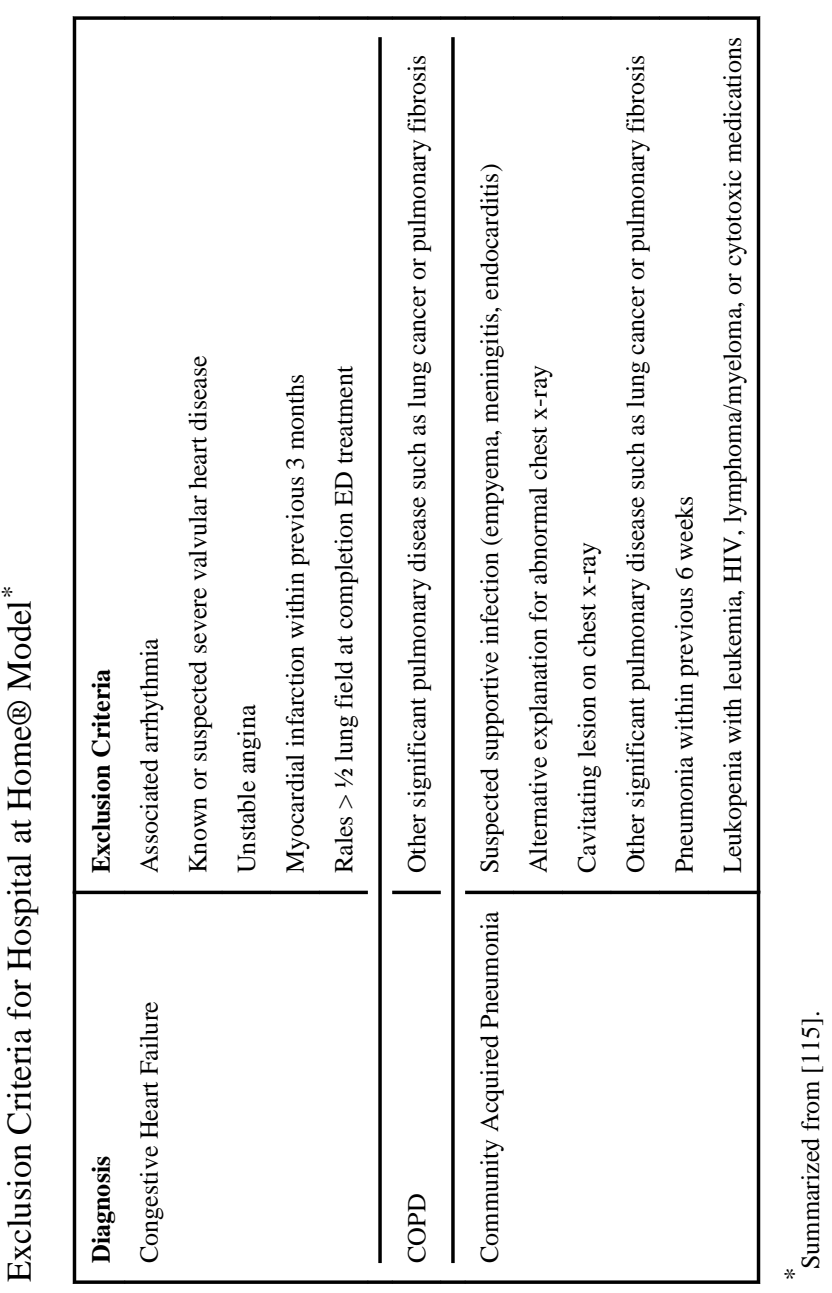

Clin Geriatr Med. Author manuscript; available in PMC 2014 February 01. 